\title{
INFLUENCE OF TEMPERATURE AND LOADING PROGRAM ON THE FATIGUE LIFE OF STEEL P91
}

\author{
Stanisław MROZIŃSKI*, Michał PIOTROWSKI*
}

*Faculty of Mechanical Engineering, University of Technology and Life Sciences in Bydgoszcz, Prof. Kaliskiego 7, 85-796 Bydgoszcz, Poland

\author{
stanislaw.mrozinski@utp.edu.pl, m.piotrowski@utp.edu.pl
}

\begin{abstract}
In this paper there are shown the results of low-cycle fatigue testing of steel P91 samples. During the testing there was conducted a fixed amplitude loading testing as well as programmed loading with various sequence degrees of the program. The testing was done in two temperatures: $\mathrm{T}=20^{\circ} \mathrm{C}$ and $\mathrm{T}=600^{\circ} \mathrm{C}$. During the testing a cyclic steel weakening was observed without a clear period of stabilization. Greater changes of the cyclic properties were observed in temperature $T=600^{\circ} \mathrm{C}$. The influence of temperature on the fatigue life was determined in this paper. This influence is dependent on the degree of strain. It's a minor one in the range of big strain and increases in the process of decreasing the degree of strain. Furthermore, the impact of the loading program type was determined on the test results and fatigue life calculations.
\end{abstract}

Keywords: Cyclic Properties, Fatigue Life, Programmed Loading, Cyclic Hardening and Weakening

\section{INTRODUCTION}

Predicting the fatigue life of technical objects during operations in increased temperatures has been a problem of many research institutes. This problem is especially relevant in the electronics industry where there is a need to renovate electric blocks, which in turn results in enormous costs. That is why it is vital to plan them optimally from the engineering stand point. Despite the fact that the process of damaging of technical objects operated in conditions of thermal and mechanical strains has been written about numerous times this issue still remains unresolved (Nagode and Zingsheim, 2004; Byrne et al. 1999; Nagesha et al. 2002). The calculation of fatigue life are related to the question of cumulative fatigue damage and the need to adopt appropriate hypothesis of summation fatigue damage. Description of the hypothesis dealing with summing up fatigue damage and the possibility of their use are discussed in detail in (Manson and Halford, 1986; Fatemi and Yang, 1998; Szala, 1988). Currently, renovations of power units are planned usually on the basis of the results of low cycle fatigue tests, and the results of calculations using the stability of the Palmgren-Miner hypothesis dealing with summing up fatigue damage (Palmgren, 1924; Miner, 1945). This hypothesis doesn't include the loading history (Mroziński, 2011). Aim of this work is the experimental verification of the hypothesis dealing with summing up fatigue damage in the programmed load conditions at elevated temperatures.

\section{TESTING DESCRIPTION}

Samples for the experiment were made out of steel P91 used in heating plants according to (Palmgren A., 1924). The samples were extracted from a heating pipe like depicted in Fig. 1a and their final dimensions - Fig. $1 \mathrm{~b}$. a)

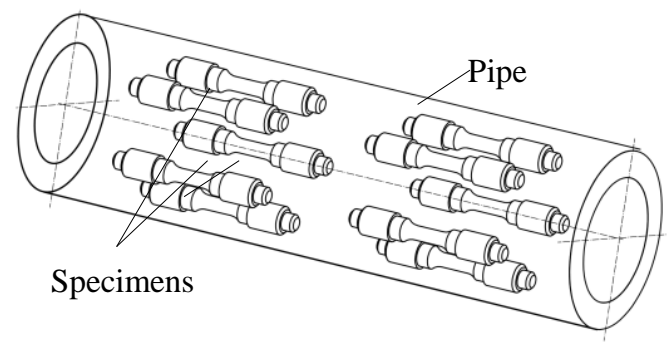

b)

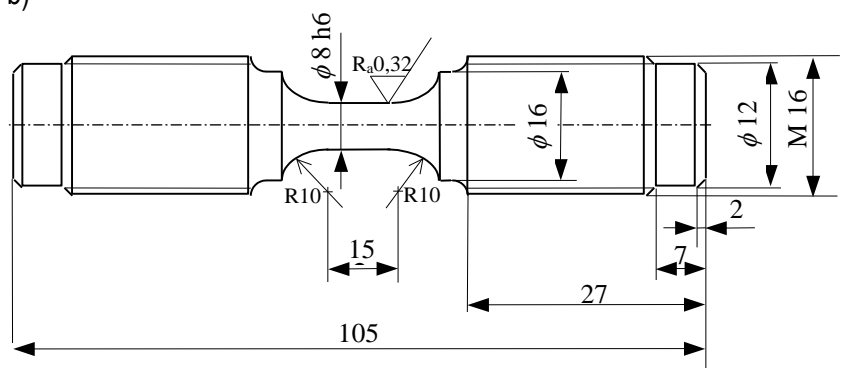

Fig. 1. Sample for testing: a) extraction places, b) sample's dimensions

The fatigue life tests were conducted in the conditions of fixed amplitude and programmed load in the two temperatures $\left(T=20^{\circ} \mathrm{C}, T=600^{\circ} \mathrm{C}\right)$. Fixed amplitude tests were done on five levels of full strain (Table 1) in the conditions of controlled strain amplitude $\left(\varepsilon_{a t}=\right.$ const $)$. There were carried out two types of programmed load: $\mathrm{L}-\mathrm{H}$ and $\mathrm{H}-\mathrm{L}$. The diagrams of the programs are shown in Tab.1. 
Tab. 1. Parameters of loading programs

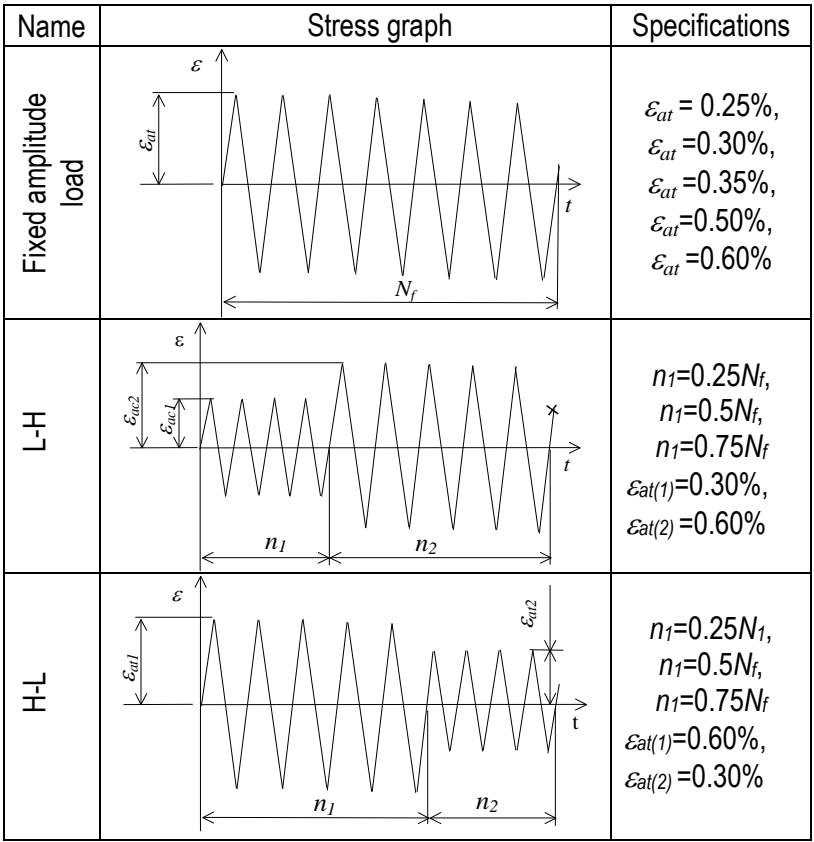

\section{TEST RESULTS AND ANALYSIS}

\subsection{Fixed amplitude fatigue life testing}

a)

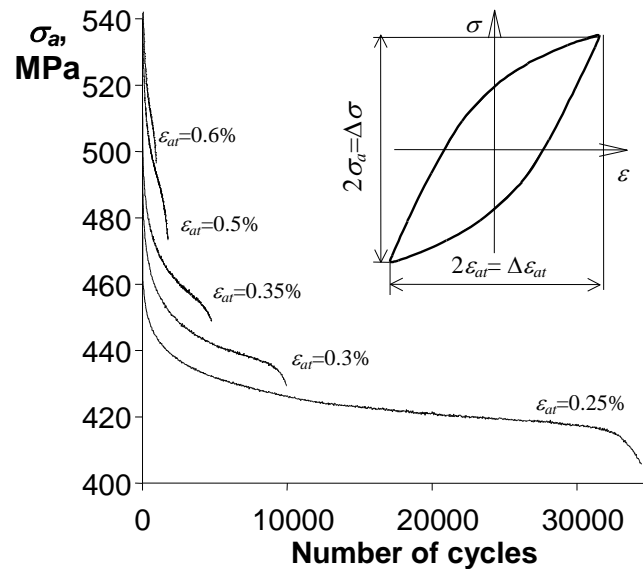

b)

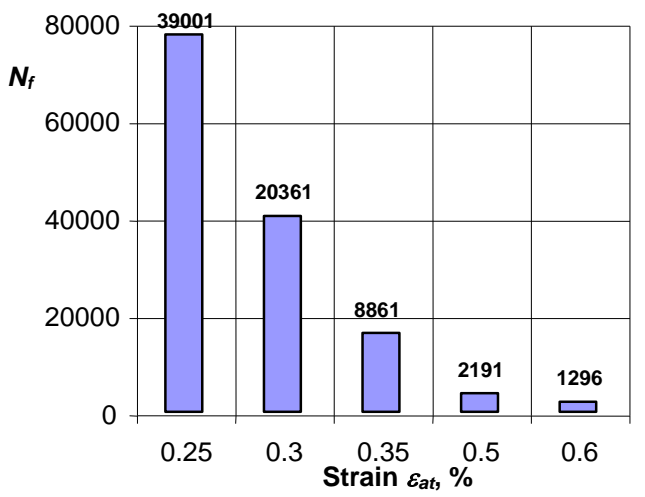

Fig. 2. Results of fatigue tests of steel $P 91$ in temperature $T=20^{\circ} \mathrm{C}$ :

a) stress $\sigma_{a}$ in the function of cycle numbers,

b) fatigue life $\mathrm{N}_{f}$ in relation to $\varepsilon_{a t}$
The results of the fatigue life testing in the fixed amplitude conditions were analyzed using two parameters of hysteresis loops used during concluding the results of a low-cycle fatigue testing according to (ASTM E606-92). These parameters include amplitude stress $\sigma_{a}$ and the range of plastic strain changes $\varepsilon_{a p}$ (Fig. 2a). Considering the final size of this article the results of fixed amplitude fatige life testing in the two temperatures were shown in Fig. 2 and 3 in the form of example graphs of the change of one of the parameters of a hysteresis loop (stress $\sigma_{a}$ ) in the function of the numbers of loading cycles.

a)

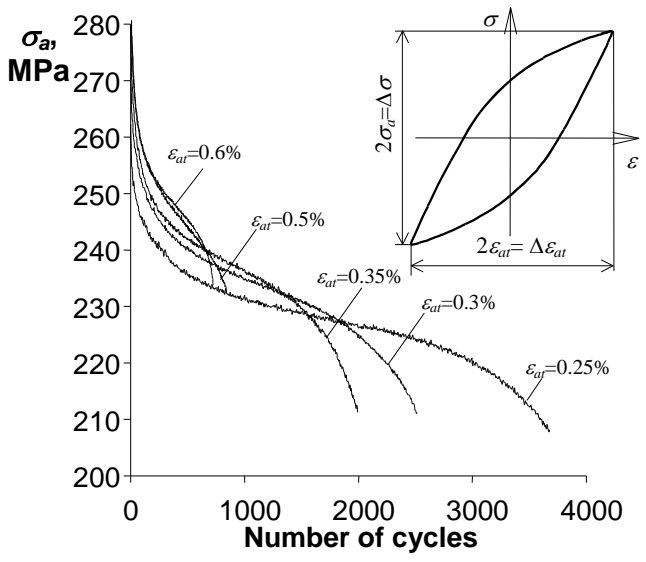

b)

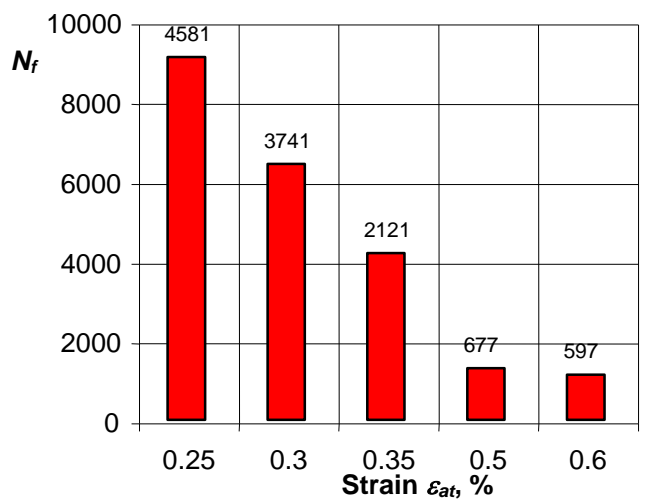

Fig. 3. Results of fatigue tests of steel $P 91$ in temperature $T=600^{\circ} \mathrm{C}$ :

a) stress $\sigma_{a}$ in the function of cycle numbers,

b) fatigue life $N_{f}$ in relation to $\varepsilon_{a t}$

Upon an analysis of the graphs in Fig. 2 and 3 it can be stated that irrespective of the temperature on all of the levels of strain steel P91 undergoes a process of cyclic weakening. A proof of the existence of this process is a constant decrease of stress amplitude $\sigma_{a}$ alongside the number of live loading cycles. The cyclic weakening in the ambient and elevated temperatures were also proved by the authors to be present in the tests of cast steel (Mroziński and Skocki, 2012).

In order to illustrate the influence of temperature on the cyclic properties of steel P91, in Fig. 4 there are grouped example function graphs of changes $\sigma_{a}$ in the function of cycle numbers on the two levels of total strain $\varepsilon_{a t}\left(\varepsilon_{a t}=0.3 \%\right.$ and $\left.\varepsilon_{a t}=0.60 \%\right)$. In Fig. 4 there are additionally marked hysteresis loops from three fatigue life periods. These were as follows: loop no. 1 for the first cycle, loop no. 2 from the period corresponding to the halfway point of the fatigue life and loop no. 3 for the last cycle on the given strain level. 
Upon an analysis of the graphs (Fig. 4) it can be stated that temporary cyclic properties (parameters of hysteresis loops) depend on the degree of fatigue damage (number of loading cycles) as well as on the temperature. The function graphs of the parameters of hysteresis loops can be divided into three characteristic stages, marked in a diagrammatic form in Fig. $4 \mathrm{~b}$ as I, II and III.

a)

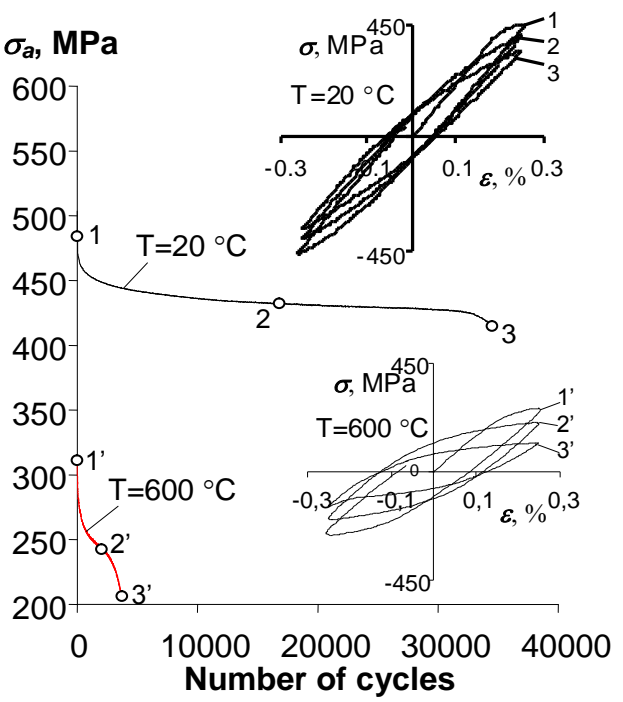

b)

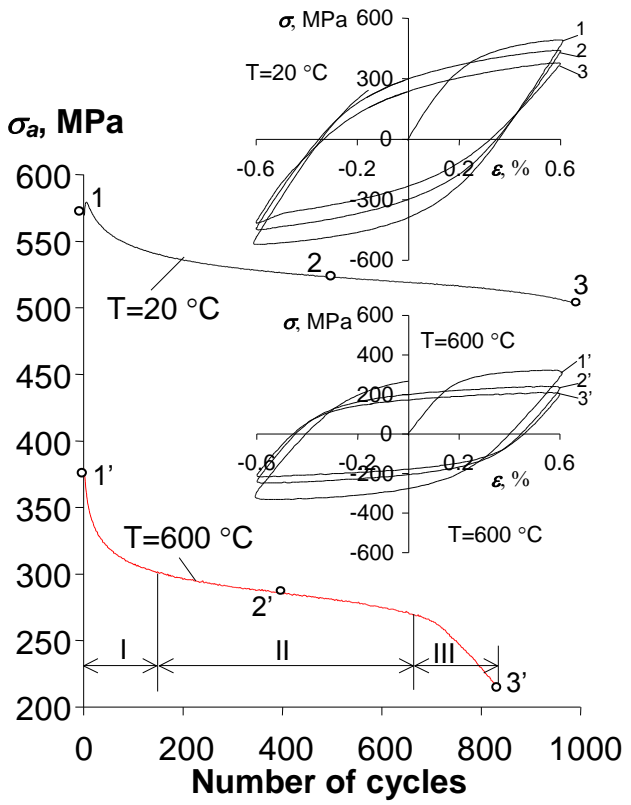

Fig. 4. Changes of $\sigma_{a}$ during the fixed amplitude loading of steel P91: a) $\varepsilon_{a t}=0.3 \%$, b) $\varepsilon_{a t}=0.6 \%$

Stage I - steel P91 is weakened greatly. It can be observed during the set level of total strain as a significant reduction of stress $\sigma$. The length of this stage depends on the level of strain and the test temperature. Stage II - steel weakens futher. The reduction of stress is much lower than in stage I. Stage III - further siginificant stress reduction. The changes of the properties are caused by microcracks which occur and add up in the material. A crack is initiated which then grows until a fatigue crack occurs.
These significant changes of the cyclic properties of steel P91 in the function of the number of cycles made it difficult to form an analytical description of the material data of the steel in the temperatures of $20 \mathrm{i} 600^{\circ} \mathrm{C}$. In order to illustrate this in Fig. 5 there are shown the results of an analytical approximation of the material data of steel $\mathrm{P} 91$ in three different fatigue life periods (points 1,2,3 and 1',2',3'- Fig. 4). The graph of cyclic strain in the three mentioned cycles was described using the Ramberg-Osgood equation:

$\varepsilon_{a}=\frac{\sigma_{a}}{E}+\left(\frac{\sigma_{a}}{K^{\prime}}\right)^{\frac{1}{n^{\prime}}}$

a)

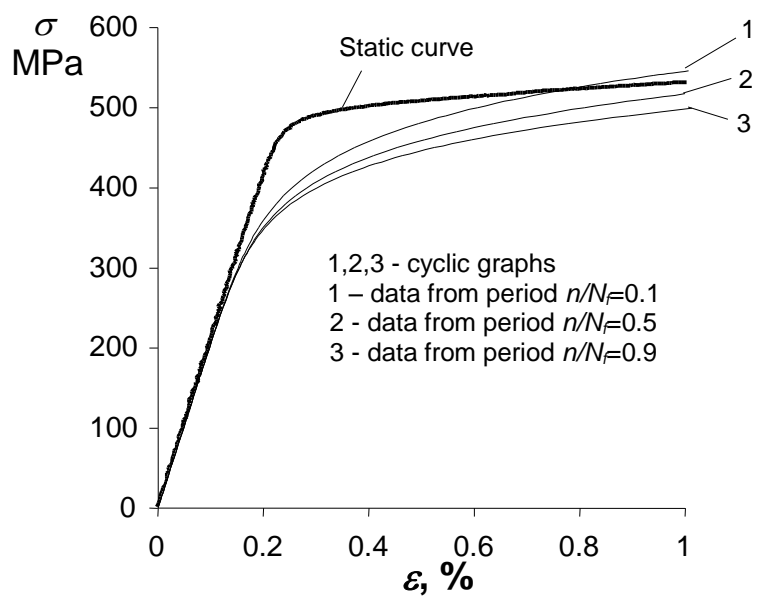

b)

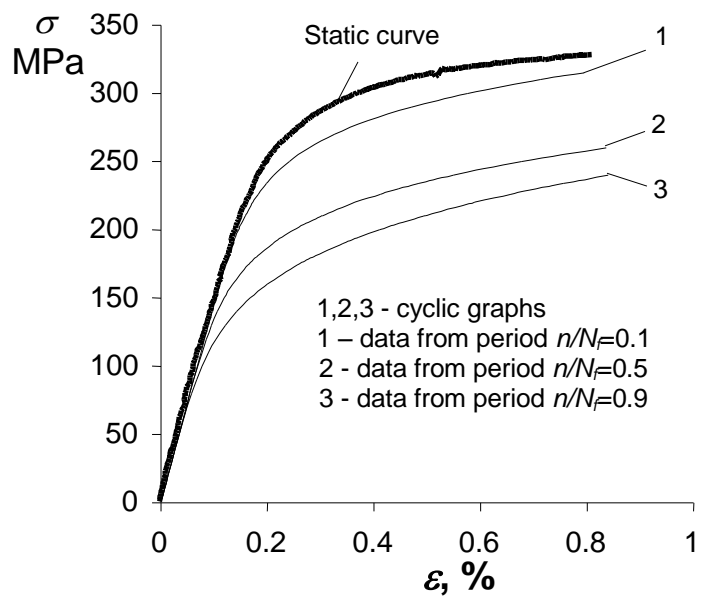

Fig. 5. Grouped graphs of static and cyclic strain: a) $\mathrm{T}=20^{\circ} \mathrm{C}$, b) $\mathrm{T}=600^{\circ} \mathrm{C}$

The graphs of cyclic strain are positioned below the graphs of static strain. The aforementioned fact is a proof of the cyclic weakening of the tested steel. Furthermore, this process is not affected by the test temperature. On the basis of the cyclic strain graphs depicted in Fig. 5 it can be stated that in the case of lack of a stabilization period of the cyclic properties there is used only temporary material data for the fatigue life calculations. The result of such approach can be a significant variance in the fatigue life values obtained from the calculations and from the testing. This fact gets much more important in the case of using this approach to determine the cyclic properties of cast steel in elevated temperatures where the range of changes in the cyclic 
properties is larger than in ambient temperatures. The proof of this is a much bigger diversification of the cyclic strain graphs in the temperature $600^{\circ} \mathrm{C}$ (Fig. 5b)

During the testing there was also observed a significant impact of the temperature on the fatigue life. In accordance with (Palmgren, 1924) the fatigue life graphs in the bilogarithmic system were approximated using the equation:

$$
\frac{\Delta \varepsilon_{a t}}{2}=\frac{\Delta \varepsilon_{a e}}{2}+\frac{\Delta \varepsilon_{a p}}{2}=\frac{\sigma_{f}^{\prime}}{E}\left(2 N_{f}\right)^{b}+\varepsilon_{f}^{\prime}\left(2 N_{f}\right)^{c}
$$

where: $b$ - exponent of fatigue life, $c$ - exponent of cyclic strain, $\sigma{ }^{\prime}$ - coefficient of fatigue life MPa, $\varepsilon f$ - coefficient of cyclic plastic strain, $E$ - Young's modulus determined from tensile testing MPa.

The exponents and coefficients present in the equation (2) were determined by taking the parameters of the hysteresis loop from the halfway point of the fatigue life $\left(n / N_{F}=0.5-\right.$ points 2 i 2 ' in Fig. 4). The fatigue life graphs obtained from the results of the approximation process of the fatigue life conducted in the two temperatures are shown in Fig. 6.

a)

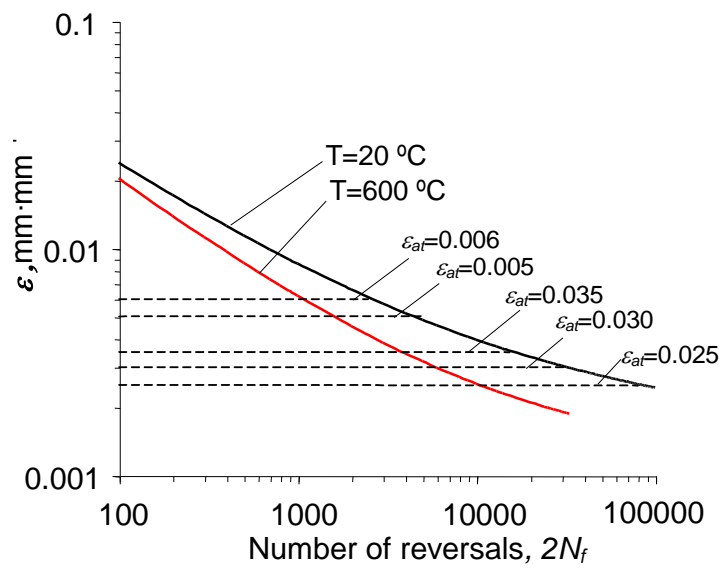

b)

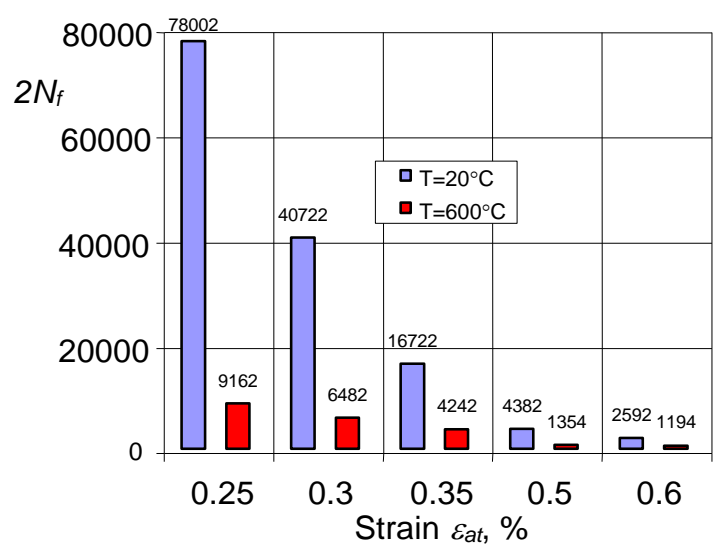

Fig. 6. Influence of temperature and degree of strain on the fatigue life: a) fatigue life graphs, b) quantitative comparison of the fatigue life

On the basis of the above graphs it can be stated that the test temperature has a great influence on the fatigue life. This influence depends on the degree of the full strain amplitude. Also, the temperature's influence is slight in the area of the biggest strain and increases with the decrease of the degree of strain.

\subsection{Programmed fatigue life testing}

The test results in the conditions of programmed stress were analyzed in the context of the basic changes of the parameters of the hysteresis loop before and after the change of the degree of the program. Similar to the fixed amplitude testing there were observed changes of the basic parameters of the hysteresis loop and a lack of a clear stabilization period. In Fig. 7 and 8 there are shown example function graphs of stress amplitude changes in the function of the number of cycles during the realization of the loading program $\mathrm{L}-\mathrm{H}$ and $\mathrm{H}-\mathrm{L}$ in temperatures $\mathrm{T}=20^{\circ} \mathrm{C}$ and $600^{\circ} \mathrm{C}$.

The changes of the cyclic properties of steel P91 after each test can be assessed up to the point of a change of the strain degree and after a change of the deformation. The function of the cyclic properties is the same in the case of the change of the strain degree like in the fixed amplitude loading. Its distinct characteristic is a strong cyclic weakening. A change of the degree of strain took place in the second stage of the changes of the cyclic properties (stage II - see section 3.1).

a)

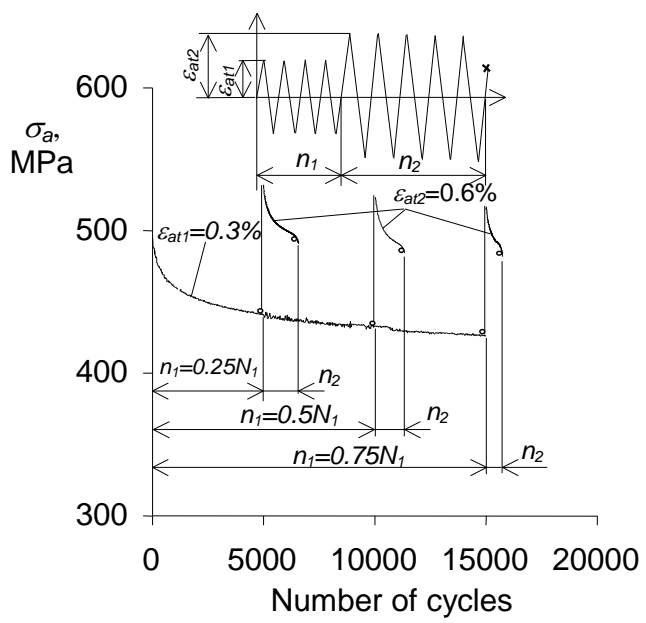

b)

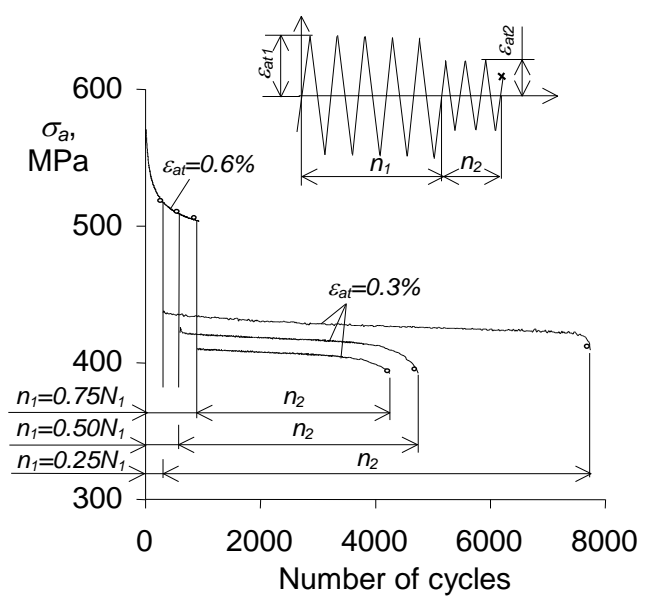

Fig. 7. Changes of $\sigma_{a}$ in the programmed loading conditions $T=20^{\circ} \mathrm{C}$ ): a) $\mathrm{L}-\mathrm{H}, \mathrm{b}) \mathrm{H}-\mathrm{L}$ 
a)

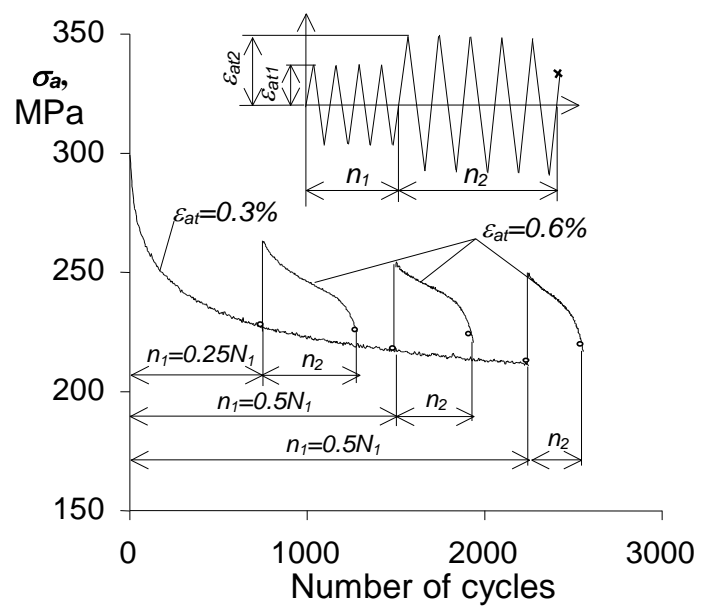

b)

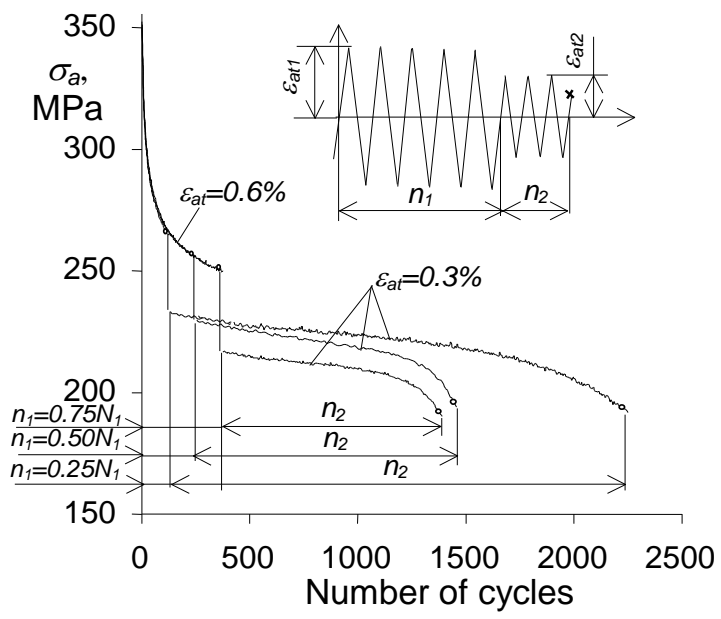

Fig. 8. Changes $\sigma_{a}$ in the programmed loading conditions $\left(T=600^{\circ} \mathrm{C}\right)$ : a) L-H, b) $H-L$

On the basis of the depicted graphs it can be stated that the cyclic properties after the change of the degree depend on the number of loading cycles realized on the first level of the program. In the case of the analyzed parameter of the hysteresis loop with the increase of the number of cycles $n_{1}$ the stress amplitude $\sigma_{a}$ gets smaller on the first degree after the change of the strain level. After this change of the strain level the steel gets more weakened. It applies to temperature $T=20^{\circ} \mathrm{C}$ as well as $T=600^{\circ} \mathrm{C}$. As expected, alongside the increase of the number of cycles $n_{1}$ on the first level, on the second level the number of cycles decreases. Nevertheless, during the testing there could be observed a distinct influence of the sequence of the loading program and temperature on the fatigue life. Higher values were observed for the sequence of program $\mathrm{L}-\mathrm{H}$.

In this paper there was conducted an experimental analysis of the Palmger-Miner (PM) hypothesis. According to the PM hypothesis a crack on the sample should occur when:

$\sum \frac{n_{i}}{N_{i}}=\frac{n_{1}}{N_{1}}+\frac{n_{2}}{N_{2}}=1$

where: $N_{1}$-number of cycles till the crack for the fixed amplitude loading on level $\varepsilon_{a t 1}, N_{2}$-number of cycles till the crack for the fixed amplitude loading on level $\varepsilon$ at2.
The results of the verification are schematically shown in Fig. 9.

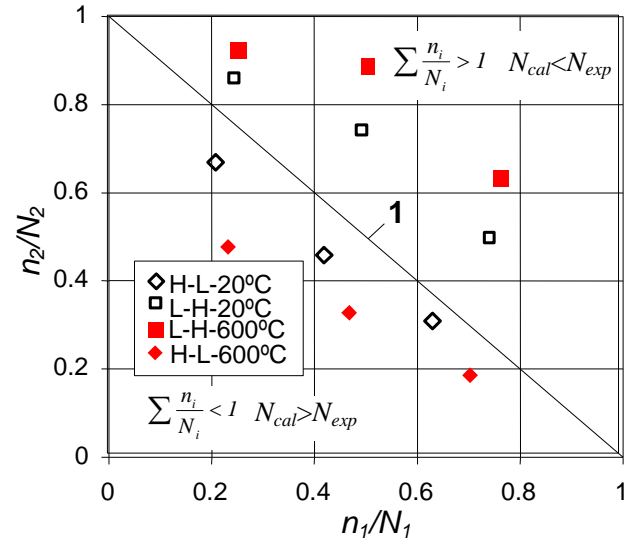

Fig. 9. Results of the verification of the hypothesis of summing up damage PM

a)

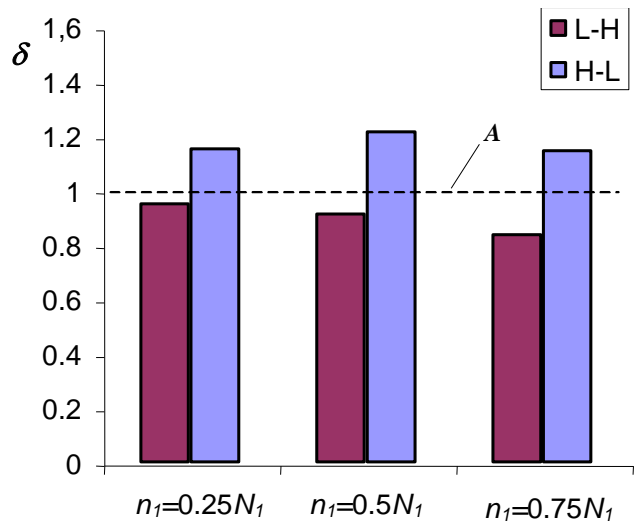

b)

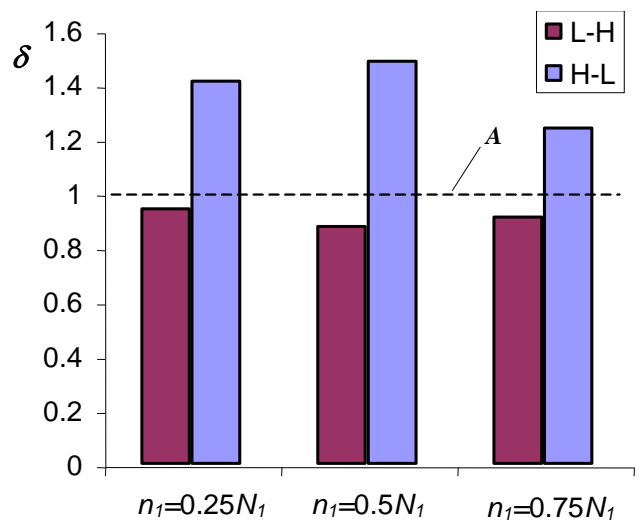

Fig. 10. Values of coeffiecient $\delta$ for the different programs:

a) $T=20^{\circ} \mathrm{C}$, b) $T=600^{\circ} \mathrm{C}$

The location of the test results on diagonal line 1 of the graph corresponds to the sum of damages $\Sigma n_{i} / N_{i}=1$ and indicates that the test results and the results of the calculations are the equal. It also shows lack of any influence of the sequence of the loading program on the fatigue life. The fact that the sum $\Sigma n_{i} / N_{i \neq 1}$ was obtained for the two sequences of the programs indicates the influence of the loading history on the results of the fatigue life. Upon the analysis of the obtained fatigue life results (Fig. 9) it has been concluded that for all the sequences $\mathrm{L}-\mathrm{H}$ the fatigue 
life values which were calculated are lower than the values determined from the testing $\left(N_{c a l}<N_{\exp }\right)$. On the other hand, the calculated fatigue life values for all the program sequences $\mathrm{H}-\mathrm{L}$ are higher than the ones obtained from the testing $\left(N_{\text {cal }}>N_{\text {exp }}\right)$. In order to arrive at the quantitative assessment of the obtained results of the fatigue life from the calculations $\left(N_{c a l}\right)$ and from the testing $\left(N_{\text {exp }}\right)$ a coefficient $\square$ was introduced:

$\delta=\frac{N_{c a l}}{N_{\text {exp }}}$

The values of coeffiecient $\delta$ are shown in the form of graphs in Fig. 10.

The values of coeffiecient $\delta$ which equal to unity (line A) simultnaeously mean that the damages sum which was calculated using the equation (3) is also equal to unity and is in accordance to the results obtained from the calculations and the testing. The damages sum $\Sigma n_{i} / N_{i} \neq 1$ obtained from the two loading program sequences $\mathrm{L}-\mathrm{H}$ i $\mathrm{H}-\mathrm{L}$ lead to an existing influence of the loading history on the fatigue life calculations. On the basis of the conducted testing it has been stated that the influence of the loading history increases in temperature $600^{\circ} \mathrm{C}$.

Results obtained in the operation results are proof steel P91 published inter alia in Junak and Cieśla $(2010,2011)$.

\section{CONCLUSIONS}

Upon an analysis of the obtained results the following conclusions can be drawn:

1. Steel P91 during the low-cycle fatigue test in temperatures 20 i $600^{\circ} \mathrm{C}$ undergoes a cyclic weakening and does not exhibit a clear stabilization period.

2. Level of strain and temperature impact the degree of changes of the cyclic properties. In temperature $600^{\circ} \mathrm{C}$ the degree of the changes of the cyclic properties is much greater than in temperature $20^{\circ} \mathrm{C}$.

3. Level of strain as well as the test temperature influence the steel's fatigue life. The influence of the temperature on the fatigue life depends on the strain level. This influence is slight in the area of very big loads and increases alongside the decrease of the strain level.

4. The occurring changes of the cyclic properties (parameters of the hysteresis loop) and a lack of a clear stabilization period of cast steel in temperatures 20 and $600^{\circ} \mathrm{C}$ make it difficult to determine the basic material data. The data's values depend on the fatigue life period taken for their calculations. The act of taking them from the halfway point of the fatigue life cause them to be only the temporary cyclic properties of cast steel from this fatigue life period.

5. The loading history has a significant impact on the fatigue life. The experimental verification of the Palmgren-Miner hypothesis indicated that its effectiveness is influenced by the loading history and the test temperature. Alongside an increase in the temperature the linear hypothesis' effectiveness decrease.

\section{REFERENCES}

1. ASTM E606-92: Standard Practice for Strain -Controlled Fatigue.

2. Byrne J., Kan N. Y. K. (1999), Hussey I.W., Harrison G.F.: Influence of sub-surface defects on low-cycle fatigue life in a gas turbine disc alloy at elevated temperature, International Journal of Fatigue, 21, 195-206

3. Fatemi A., Yang L. (1998), Cumulative Fatigue Damage and Life Prediction Theories: A Survey of the State of the Art for Homogeneous Materials, International Journal of Fatigue, 20, 9-34.

4. Junak G., Cieśla M. (2010), Low cycle life at graded load for steel in power generators, Energetyka, 21, 74-77 (in Polish).

5. Junak G., Cieśla M. (2011), Effect of graded loads on low cycle durability of steel P91 i P92 used in power generation, Inżynieria materiałowa, 32, 5, 862-867 (in Polish).

6. Junak G., Cieśla M. (2011), Low-cycle fatigue of P91 and P92 steels used in the power engineering industry, Archives of Materials Science and Engineering, vol. $48 \mathrm{nr}$ 1, 19-24.

7. Manson S. S., Halford G. R. (1986), Re-Examination of Cumulative Fatigue Damage Analysis - an Engineering Perspective, Engineering Fracture Mechanics, 25(5/6), 539-571.

8. Miner M. A. (1945), Cumulative Damage in Fatigue, Transactions of the American Society of Mechanicals Engineers Journal of Applied Mechanics, 67, 159-164.

9. Mroziński S. (2011), The influence of loading program on the course of fatigue damage cumulation, Journal of Theoretical and Applied Mechanics, 49, 1, 83-95.

10. Mroziński S., Skocki R. (2012), Influence of temperature on the cyclic properties of martensitic cast steel, Materials Science Forum, Vol. 726, 150-155.

11. Nagesha A., Valsan M., Kannan R., Bhanu Sankara Rao K., Mannan S.L. (2002), Influence of temperature on the low cycle fatigue behaviour of a modified $9 \mathrm{Cr}-1$ Mo ferritic steel, International Journal of Fatigue, 24, 1285-1293.

12. Nagode M., Zingsheim M. (2004), An online algorithm for temperature influenced fatigue life estimation: strain-life approach, International Journal of Fatigue, 26, 155-161.

13. Palmgren A. (1924), Die Lebensdauer von Kugellagem Verfahrenstechnik, Berlin, 68, 339-341.

14. Szala J., Fatigue damage summation hypothesis, University ATR in Bydgoszcz (in Polish).

Acknowledgements: Scientific work funded by the Ministry of Education and Science in the years $2011 \div 2013$ as a research project No 1215/B/T02/2011/40. 